\title{
A RUNWAY SURFACE MONITOR USING INTERNET OF THINGS
}

\author{
Amedeo Troiano - Eros Pasero *
}

\begin{abstract}
The monitoring of runway surfaces, for the detection of ice formation or presence of water, is an important issue for reducing maintenance costs and improving traffic safety. An innovative sensor was developed to detect the presence of ice or water on its surface, and its repeatability, stability and reliability were assessed in different simulations and experiments, performed both in laboratory and in the field. Three sensors were embedded in the runway of the Turin-Caselle airport, in the north-west of Italy, to check the state of its surface. Each sensor was connected to a GPRS modem to send the collected data to a common database. The entire system was installed about three years ago, and up to now it shows correct work and automatic reactivation after malfunctions without any external help. The state of the runway surface is virtual represented in an internet website, using the Internet of Things features and opening new scenarios.
\end{abstract}

K e y w ords: internet of things, ice detection, water detection, sensor, remote monitoring, runway surface

\section{INTRODUCTION}

The monitoring of ice formation finds important applications in many different fields. A correct assessment of the environmental conditions may contribute to enhance traffic safety on roads or to alert people walking on walkways [1]. The evaluation of the environmental conditions on road and runway surfaces is important to reduce maintenance costs of highways and airports [2]. As a matter of fact, an accurate indication of surface conditions helps agencies to efficiently plan the maintenance procedures (especially during winter) and to decrease the use of chemical, sand, and salt.

Different technologies were developed to detect the surface conditions, depending on the application. Some techniques put the sensor directly in contact with the pavement surface, others allow for a remote sensing. Different sensors were developed exploiting different physical principles, e.g. concerning vibrations [3], electro-optics [4], fiber-optics [5], radio frequencies [6], micro-mechanics [7], ultrasounds [8], and inductive effects [9].

An innovative, low cost, sensor was introduced in [10] to detect directly water and ice on its exposed surface, based on a capacitance measurement, estimating the relative permittivity of the material placed over it. The sensor is robust enough to be directly embedded in the pavements of a runway. Moreover, the sensor measures the temperature on its surface [10]. The sensor was investigated by simulations and experiments, both in laboratory [11] and in the field [12] [13] [14] [15], and results show that it can provide indications in line with the environmental conditions, identifying properly the ice formation and indicating the wet state during both rain, snow and fog.

Three sensors were embedded in the $4 \mathrm{~km}$ long runway of the Turin-Caselle international airport (north-west Italy) to check the state of its surface. The sensors were placed far from each other to monitor different positions of the runway, and each sensor was equipped with a GPRS modem which allows to send the collected data to a remote database through Internet.

Internet of Things is a novel paradigm in the scenario of modern wireless telecommunications. The basic idea of this concept is the presence of a variety of smart objects (such as RFID tags, sensors, actuators, and mobile phones) which, through an unique addressing scheme, are able to interact and cooperate with each other to reach common goals that are provided to the users using Internet [16] [17].

The paper presents an innovative system for the monitoring of the state of the runway surface at Turin-Caselle airport, in Italy. A user-friendly presentation of the data in websites using the Internet of Things concepts is introduced.

\section{METHODS}

\subsection{The sensor}

The sensor for the estimation of the state of the runway surface is based on a capacitance measurement [10], [19]. In general, the capacitance value of an electrode assembly depends on the geometrical configuration and dimensions of the electrodes, and on the relative permittivity and thickness of the material placed between them. Moreover, the relative permittivity depends on temperature and measurement frequency [18]. Figure 1 shows the relation between relative permittivity and measurement frequency for water, ice and air. The relative permittivity of water at $25^{\circ} \mathrm{C}$ is substantially constant up to about $10^{9} \mathrm{~Hz}$ and decreases within the range from $10^{9}$ Hzto $10^{10}$ $\mathrm{Hz}$. On the other hand, the relative permittivity of ice at $-10^{\circ} \mathrm{C}$ is substantially constant up to about $1 \mathrm{kHz}$, and

\footnotetext{
* Dipartimento di Elettronica, Politecnico di Torino, Corso Duca degli Abruzzi, 24 10129 Torino, Italy, amedeo.troiano@polito.it eros.pasero@polito.it
} 
decrease in the range from $2 \mathrm{kHz}$ to $20 \mathrm{kHz}$. The relative permittivity of air can be assumed equal to 1 and constant for each frequency and temperature.

Relative permitivity

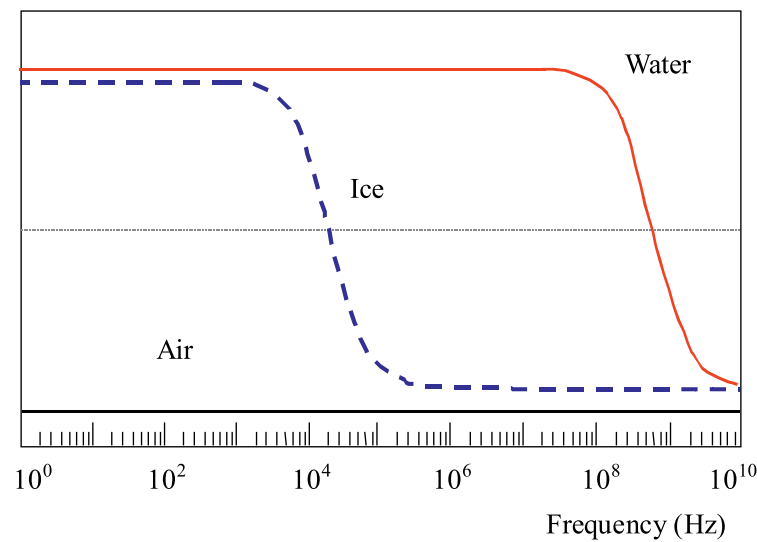

Fig. 1. Relative permittivity of water (at $25^{\circ} \mathrm{C}$ ), air, and ice (at $-10^{\circ} \mathrm{C}$ ) as a function of frequency

Therefore, at low frequencies (lower than $1 \mathrm{kHz}$ ) the relative permittivity of water and ice are similar, while the relative permittivity of air is different from the others. Instead, at high frequencies (between $100 \mathrm{kHz}$ and $100 \mathrm{MHz}$ ) the relative permittivity of air and ice are similar, while the relative permittivity of water is different from the others. Thus, it is possible to distinguish between water, ice and air performing two measurements of relative permittivity, at low $(200 \mathrm{~Hz})$ and high $(20 \mathrm{MHz})$ frequencies, as summarized in Tab. 1.

Table 1. Revealed substance as a function of the relative permittivity values at $200 \mathrm{~Hz}$ and $20 \mathrm{MHz}$

\begin{tabular}{ccc}
\hline $\begin{array}{c}\text { Relative } \\
\text { permittivity } \\
\text { at } 200 \mathrm{~Hz}\end{array}$ & $\begin{array}{c}\text { Relative } \\
\text { permittivity } \\
\text { at } 20 \mathrm{MHz}\end{array}$ & $\begin{array}{c}\text { Revealed } \\
\text { substance }\end{array}$ \\
\hline HIGH & HIGH & Water \\
HIGH & LOW & Ice \\
LOW & LOW & Air \\
\hline
\end{tabular}

The currently available sensor is shown in Fig. 2(a), it consists of a pair of concentric conductive electrodes, with dimensions shown in Fig. 2(b), which constitute the sensing device, and a transfer charge circuit for capacitance measurement [10]. The transfer charge circuit was used for the design of the sensor since it allows measurements at different frequencies, as required for the distinction between water, ice, and air.

Both the electrodes of the sensor and the transfer charge circuit are implemented on printed circuit boards, and they are directly connected, as shown in Fig. 2(c). The sensor is built using low cost and low power components. Using the transfer charge circuit, the capacitance value of the electrode assembly $C_{X}$, at each frequency, can be calculated as

$$
C_{X}=C_{S} \frac{V_{S}}{V_{R}}
$$

where $C_{S}$ and $V_{R}$ are the reference capacitance and voltage source, respectively, and $V_{S}$ is the measured voltage $[10]$.

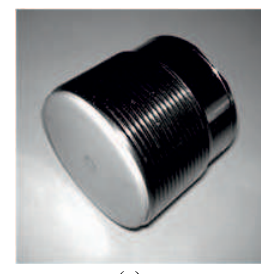

(a)

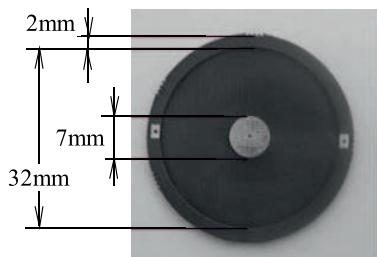

(b)

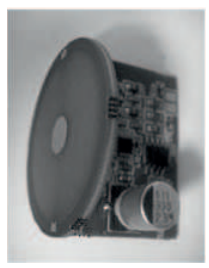

(c)
Fig. 2. (a) - the currently available prototype of the sensor, (b) the concentric conductive electrodes, (c) - the assembled electronic circuit of the sensor

In the sensor are included an automatic calibration procedure to prevent error in the data due to parasitic capacitances [10], and a temperature sensor to allow for variations of the relative permittivity with temperature. A layer $3 \mathrm{~mm}$ thick of Arnite was mounted over the electrodes for protection purposes, and the printed circuit boards of the electrodes and the transfer charge circuit were inserted into a IP68 metallic box filled with resin, which protects from infiltration of water or chemical agents. In the bottom of the sensor, an IP68 connector is used for getting the power supply and for the transmission of the revealed states to a common database through the GPRS based data acquisition system described in the next paragraph.

\subsection{The GPRS based data acquisition system}

The GPRS based data acquisition is a digital system that acquires capacitance values from the sensor and expand them to produce the runway state. Moreover, it configures the GPRS modem for the transmission of the revealed states to the remote database. The data acquisition system is designed to be connected with up to 12 sensors.

By means of the GPRS modem, the system gains access to internet that gives the opportunity to send the collected data to a remote database. During the design of the system, a particular attention was put on a set of self-reactivation functions since the particular environment (an airport or a road) in which the sensor is used makes hard reaching the system in the case of malfunctions. An antenna was added to the GPRS module to increase the range.

Three sensors were embedded in the runway of the Turin-Caselle airport, in Italy, to check the state of its surface. Each sensor was connected to a GPRS based data acquisition system to wirelessly transmit information about the state of the runway to a remote database 


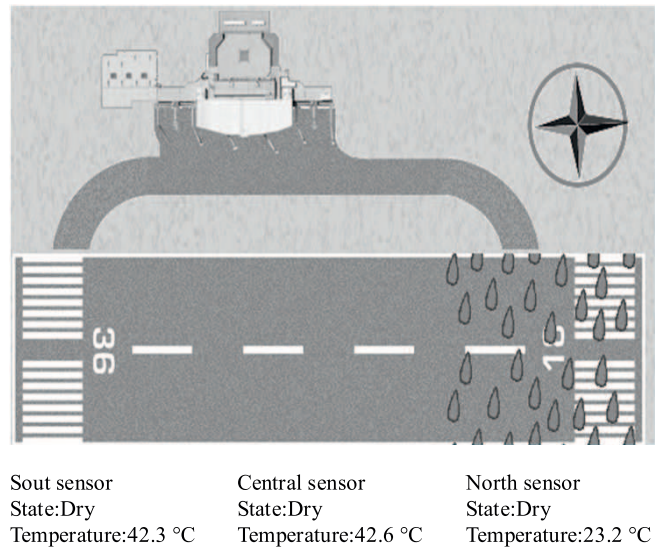

Fig. 3. Current state of the runway indicated in a web page

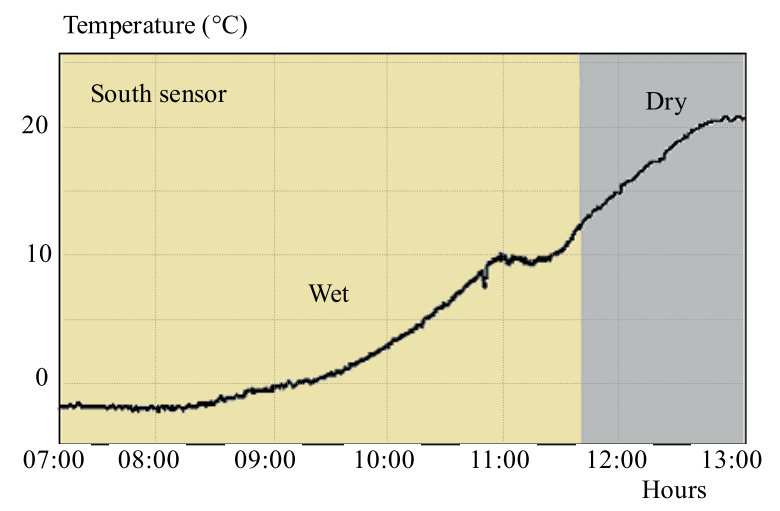

Temperature $\left({ }^{\circ} \mathrm{C}\right)$

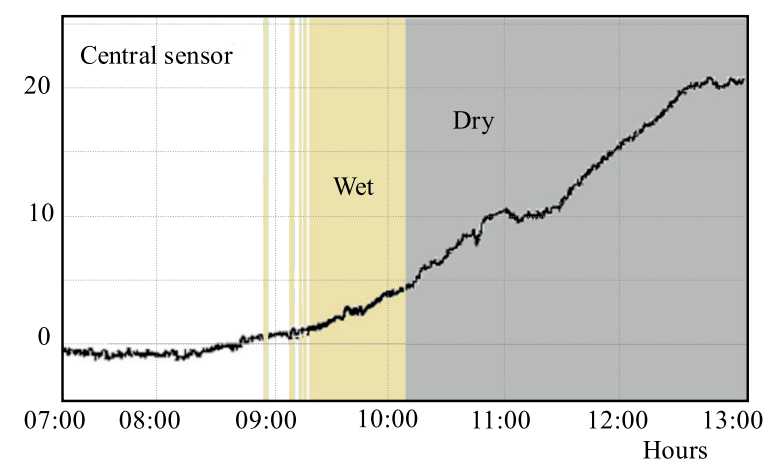

Fig. 4. Last 24 hours state and temperature indicated in a web page

implemented in MySQL, and hosted in the central server of the Polytechnic of Turin. These information are then presented on web pages using the Internet of Things features, as described in the next paragraph.

\subsection{Presentation of the data in a web site using Internet of Things}

To make the information about the state of the runway of the Turin-Caselle airport available to everyone, respecting the Internet of Things concepts [16] [17], two web pages were developed. Data stored in the MySQL database are accessed by a Javascript script that updates web pages according to the received values.
The first web page (Fig. 3) displays the state of the runway surface detected by the three sensors. The runway is represented in the middle of the page, divided into three sections (north, central, and south); each of them contains a sensor. According to the detected state, each section shows a different dynamic image (nothing to indicate dry, rain to indicate wet, and ice crystals to indicate icy). Old data of a summer day were used in Fig. 3, in which the rain covered only the north section of the runway, indicated by the wet state. Textual information is also added at the end of the page, together with the temperature value measured by the sensor.

Moreover, a second web page was implemented (Fig. 4) to provide detailed information about the last 24 hours. Both the temperature (black line) and the state of the runway (the background color) are indicated in the web page. For simplicity, the 24 hours information are split in 4 pages, each of them shows 6 hours (four images per sensor per day), with the possibility to switch using two lateral buttons (not showed in Fig. 4). Figure 4 shows the data collected by the south and the central sensors from about 7 am to about 13 am of a winter day. The ground temperature raised from about $-2{ }^{\circ} \mathrm{C}$ to about $20^{\circ} \mathrm{C}$ for both sensors. The south sensor sensed the wet state till an half past 11, then the surface dried. On the other hand, the central sensor sensed the icy state till 9 oclock, then the ice melted and then, after about one hour, the surface dried.

These information are available for people in charge of maintenance, for runway services, for security authority and for public using a different graphical representation.

\section{RESULTS}

\subsection{Reliability of the sensor}

The reliability of the state revealed by the sensor was investigated during laboratory experiments, applying the same environmental conditions to more sensors and evaluating the dispersion of the time instants in which phase changes of water were detected. Nine sensors were placed at the same time in a climatic chamber. At the beginning of the experiment, sensors were tested with room conditions, (temperature at $25^{\circ} \mathrm{C}$ and relative humidity at $50 \%$ ), for approximately 10 minutes in order to wait that the indications of the sensor became stationary. Then, $1 \mathrm{~mm}$ of tap water was placed over each sensor. Sensors were left at room conditions for 10 minutes. Then, the climatic chamber was arranged to reach $-20^{\circ} \mathrm{C}$ with $-1{ }^{\circ} \mathrm{C}$ per minute temperature gradient. During this period, water placed over sensors froze. The climatic chamber kept the temperature at $-20^{\circ} \mathrm{C}$ for approximately 10 minutes and then it was arranged to reach $25^{\circ} \mathrm{C}$ with a temperature gradient of $1^{\circ} \mathrm{C}$ per minute. During this period, the ice formed over the sensors melt. The climatic chamber kept the temperature of $25^{\circ} \mathrm{C}$ for approximately $10 \mathrm{~min}$ utes. Then each sensor was dried. Data were acquired for 

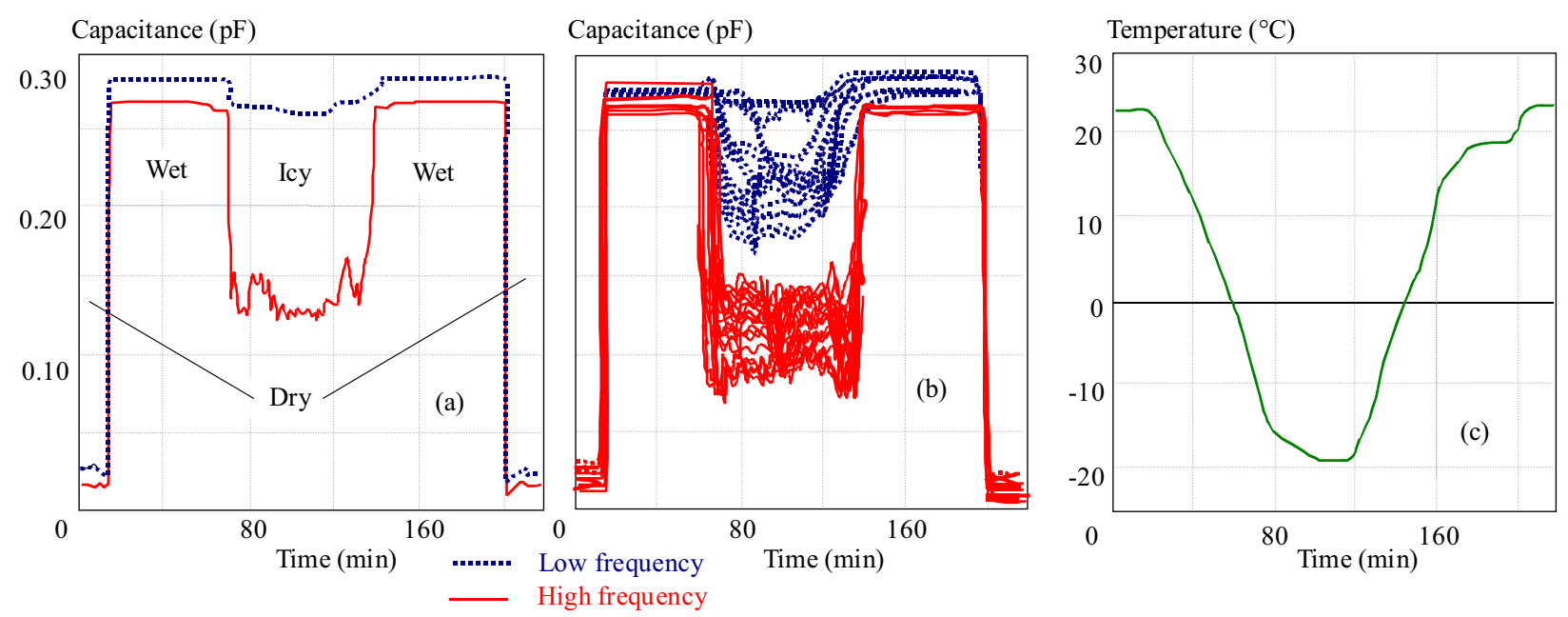

Fig. 5. Statistical analysis of the laboratory experiment: (a) - values of capacitance (raw data) obtained for a sensor, (b) - values of capacitance (raw data) obtained for nine sensors, and (c) - temperature of the climatic chamber

additional 10 minutes, with a temperature at $25^{\circ} \mathrm{C}$ and humidity at $50 \%$.

Values of capacitance (raw data) obtained from a sensor during the experiment at different measurement frequencies are shown in Fig. 5(a). Variations of the values of capacitance in different states of the sensor are clearly visible. During the dry state, the values of capacitance are close to zero. During the wet state, the values of capacitance at high and low frequencies are close to $0.3 \mathrm{pF}$, and there is no distinction between different measurement frequencies. During the icy state, the values of capacitance at high frequency are close to $0.15 \mathrm{pF}$ while at low frequency are close to $0.3 \mathrm{pF}$, so the value of capacitance can be easily distinguished for different measurement frequencies. Values of capacitance (raw data) obtained for each sensor during the experiment (high and low measurement frequencies) are shown in Fig. 5(b). Differences among different sensors are visible, due to manufacturing tolerances and to low precision in controlling the thickness of the water layer. Differences of the estimated times of phase transition of water among different sensors were in the order of a few minutes. Temperature of the climatic chamber during the experiment is shown in Fig.5 (c).

\subsection{Reliability of the GPRS based data acquisi- tion system}

Knowledge of observed data is required for the use of them to improve the runway safety. The essence of these data is to allow the runway de-ice services to spread deicing substances when ice is detected. The reliability of the GPRS based data acquisition system, and the selfreactivation features, was tested using the data stored in the MySQL database from each sensor about a time period. The resulting outage trend of the system was studied. Three bar diagrams are presented in Fig. 6, one for each sensor, showing the statistics of functionality during a month. Each bar represents a day, while on the $y$-axis there is the time of the day.

If the malfunction is common to all sensors, a database problem can be supposed (like the ones of October 3-rd and October 10-th). Excluding database problems, the only noticeable malfunctions were between October 7-th and October 9-th, when a network coverage problem is supposed (only for the north and central sectors of the runway). Diagrams of Fig. 7 are referred to the month of October 2012, however similar behavior is obtained for other time periods in which the device was used.
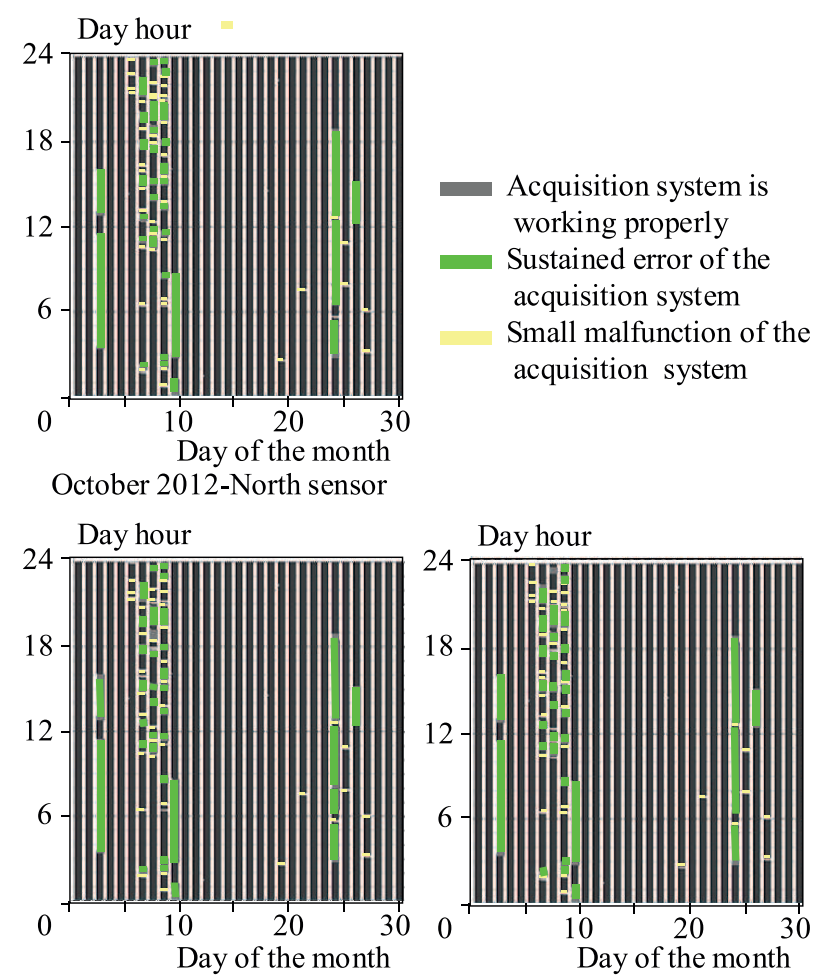

October 2012-Central sensor October 2012-South sensor

Fig. 6. Statistics for the GPRS based data acquisition system 


\section{CONCLUSION}

An innovative system to monitor the state of the runway surface at the Turin-Caselle airport, in Italy, was presented. The data are shown on web pages using the Internet of Things features, allowing the users of the airport to online monitor the state of the runway, wherever they are. The system was installed about three years ago showing correct working and automatic reactivation after malfunctions without any external help.

\section{Acknowledgment}

This project has been financially supported by Piedmont Region research project AWIS, Airport Winter Information System. The authors wish to thank Lorenzo Gusman, SAGAT Engineering, for his precious cooperation in the runway operations.

\section{REFERENCES}

[1] LEE, N. S. T.-KARIMI, H. A.-KRAKIWSKY, E. J. : Road information systems: impact of geographic information systems technology to automatic vehicle navigation and guidance, Proceedings of the Conference on Vehicle Navigation and Information Systems, Toronto, Canada, 11-13 September 1989.

[2] PASERO, E.-MONIACI, W.-RAIMONDO, G. : AWIS: an Airport Winter Information System, Proceedings of the XIV Standing International Road Weather Commission (SIRWEC), Prague, Czech Republic, 14-16 May 2008.

[3] BARRE, C.-LAPEYRONNIE, D.-SALAUN, G. : Ice detection assembly installed on an aircraft, US Patent 7000871, 21 February 2006.

[4] ANDERSON, M. : Electro-optic ice detection device, US Patent 6425286, 30 July 200.

[5] WEI, L.-JIE, Z.-LIN, Y.-HONG, Z.alinfo A fiber-optic solution to aircraft icing detection and measurement problem, Proceedings of International Conference on Information Technology and Computer Science (ITCS), Kiev, Ukraine, 25-26 Jul 2009.

[6] ABAUnZA, J. T.: Aircraft icing sensors, US Patent 5772153, 30 July 1998

[7] DEANNA, R.: Ice detection sensor. US Patent 5886256, 23 March 1999.

[8] GAO, H.-ROSE, J. L.: Ice detection and classification on an aircraft wing with ultrasonic shear horizontal guided waves, Transactions on Ultrasonics, Ferroelectrics, and Frequency Control 56 No. 2 (2009), 334-344.

[9] LEE, H.-SEEGMILLER, B.alinfo Ice detector and deicing fluid effectiveness monitoring system, US Patent 5523959, 4 June 1996 .

[10] TROIANO, A.-PASERO, E.-MESIN, L. : New System for Detecting Road Ice Formation, IEEE Transactions on Instrumentation and Measurement 60 No. 3 (2011), 1091-1101.
[11] MESIN, L.-TROIANO, A.-PASERO, E.: In Field Application of an Innovative Sensor for Monitoring Road and Runway Surfaces, Proceedings of International Conference on Sensor Device Technologies and Applications (SENSORDEVICES), Venice, Italy, 18-25 July 2010.

[12] TROIANO, A.-PASERO, E.-MESIN, L. : An innovative water and ice detection system for road and runway surfaces monitoring, Proceedings of Conference on PhD Research In Microelectronics \& Electronics (PRIME), Berlin, Germany, 18-21 July 2010.

[13] TROIANO, A.-PASERO, E.-MESIN, L.: In the Field Application of a New Sensor for Monitoring Road and Runway Surfaces, Sensors \& Transducers No. 10 (2011), 71-83.

[14] TROIANO, A.-PASERO, E.-MESIN, L. : Detection of Ice Formation over a Road Surface,, Proceedings of International Conference on Sensor Device Technologies and Applications (SENSORDEVICES), Nice/Saint Laurent du Var, France, 21-27 August 2011.

[15] TROIANO, A.-PASERO, E.-MESIN, L. : Remote Monitoring of Ice Formation Over a Runway Surface,, Proceedings of the XVI Standing International Road Weather Commission (SIRWEC), Helsinki, Finland, 23-25 May 2012.

[16] ATZORI, L.-IERA, A.-MORABITO, G.: The Internet of Things: A survey, Computer Networks 54 No. 15 (2010), $2787-2805$.

[17] MIORANDI, D.-SICARI, S.-DEPELLEGRINI, F.-CHLAMTAC, I. : Internet of things: Vision, applications and research challenges jour Ad Hoc Networks.

[18] VONHIPPEL, A.: The dielectric relaxation spectra of water, ice, and aqueous solutions, and their interpretation: critical survey of the status-quo for water, IEEE Transactions on Electrical Insulation 23 No. 5 (1988), 801-840.

19] PASERO, E.-RICCARDI, M.: Multi-frequency capacitive measurement device and method of operating the same, Patent US 7205780, (2006).

Received 20 September 2012

Amedeo Troiano ( $\mathrm{PhD}$, Ing) received the MS degree in 2006 and received the $\mathrm{PhD}$ in 2010 in Electronics Engineering from Politecnico di Torino, Italy. Since 2010 he is a Fellow at the Neuronica Laboratory of the Department of Electronics, Politecnico di Torino. His research interests include memristors, design of analogue and digital electronic systems, hardware/software co-design, and intelligent sensor design.

Eros Pasero (Prof, Ing) received the MS degree in Electronics Engineering from Politecnico di Torino, Italy in 1980. From 1987 to 1990 he was Professor of Electronics at II University of Roma. Since 1991 he has been with the Department of Electronics, Politecnico di Torino, where he founded the Neuronica Laboratory and is Professor of Electronics. Prof. Pasero was v. General Chairman of IJCNN2000, General Chairman of Sirwec 2006 conferences and founder of SIREN, the Italian society of Neural Networks, His current research includes neural networks modelling and simulation, memristors, neuromorphic circuits, electronic sensors design and hardware circuits implementations. 